\title{
O legado de Friedrich List e sua influência sobre a integração econômica europeia*
}

\section{Friedrich List's legacy and his influence on the European economic integration}

\author{
Flávio dos Santos Oliveira ${ }^{\star}$
}

Resumo: $O$ artigo detalha o entendimento de Friedrich List sobre as vantagens e proventos advindos da união aduaneira, considerando-se o caso do Zollverein. Ressaltam-se as contribuições da Friedrich List-Gesellschaft (FLG) (Sociedade Friedrich List) quanto à proposição de medidas factíveis para a reestruturação da economia alemã após a Grande Depressão (1929). Examinam-se, em seguida, aspectos da Anschauliche Theorie (Teoria Intuitiva) do eminente professor Edgar Salin, a fim de elucidar sua concepção de teoria geral da economia. Por fim, colocase em evidência o papel desempenhado pela List-Gesellschaft (LG) (Sociedade List) no que concerne à fundamentação teórica da integração econômica europeia. Constata-se que, apesar de todo o aporte fornecido pela LG para o fortalecimento da Comunidade Econômica Europeia, o argumento capital de List em matéria de livre comércio parece, de certo modo, não ter sido apreciado em toda sua extensão pelo grupo.

Palavras-chave: Zollverein. Friedrich List-Gesellschaft. List-Gesellschaft. Teoria Intuitiva. Integração econômica europeia.

\begin{abstract}
The article details Friedrich List's understanding about the advantages and earnings resulting from the customs union, considering the case of Zollverein. Next, Friedrich List-Gesellschaft's contributions in regard to the devising of feasible measures for restructuring the German economy after the Great Depression (1929) are put into evidence.Afterwards, Edgar Salin's Anschauliche Theorie (Intuitive Theory) is examined in order to better understand his conception of general theory of economics. Finally, the role played by List-Gesellschaft (LG), in founding the theoretical basis of European economic integration is outlined. It is noteworthy that despite all the support provided by LG for the strengthening of the European

\footnotetext{
* Submissão: 21/12/2020 | Aprovação: 10/08/2021 | DOI: 10.29182/hehe.v24i3.784

$\star \star$ Departamento de História, Universidade Federal do Espírito Santo (UFES), Brasil | ORCID: 00000002-2591-9019 | E-mail: flaviosantosoliveira2@gmail.com
} 
Economic Community, List's main argument on free trade seems to have, to some extent, not been fully appreciated by the group.

Keywords: Zollverein. Friedrich List-Gesellschaft. List-Gesellschaft. Intuitive Theory. European economic integration.

JEL: B10. B15. B31. 


\section{Introdução}

Friedrich List (1789-1846) é comumente apresentado como representante do protecionismo, ao preconizar restrições temporárias às importações como forma de desenvolver a economia nacional. Esse, no entanto, é um modo simplório de interpretar o pensamento do economista suábio. List foi um dos fundadores do grande movimento em prol do livre comércio entre os Estados Alemães, o que eventualmente extinguiu mais alfândegas do que até mesmo os turbilhões políticos da ocupação francesa. Durante sua atividade como editor do Württembergische Archive e no Volksfreund aus Schwaben, List lançou as bases do Zollverein com o fito de abolir tarifas e pedágios entre os vários Estados Alemães e estabelecer um sistema comercial e alfandegário comum para toda Alemanha (List, 1815; Furniss, 1909; Chang, 2007). Posteriormente, na década de 1950, o mesmo Zollverein foi tomado como paradigma a ser seguido no processo de integração econômica europeia, ainda que ignorando um conjunto de fatores que concorreram para o seu sucesso. ${ }^{1}$

Naquela época, os acordos comerciais assinados entre os diversos países europeus visavam superar as rivalidades e os ressentimentos gerados pelas duas grandes guerras, buscando no fortalecimento econômico um meio para fazer frente ao rápido crescimento do Japão e, sobretudo, dos Estados Unidos. Entrementes, estudiosos como Edgar Salin forneciam suporte teórico para o esclarecimento de questões importantes a respeito da união aduaneira, como a uniformização dos pedágios de trânsito, flexibilização das taxas de câmbio, política de preços, extensão do mercado, unificação monetária etc. Salin, na verdade, é considerado um dos mais influentes eruditos alemães do século passado, com estudos que abrangem vasto campo do saber, com destaque para Filosofia, História e, principalmente, Economia, em que conduz um estudo histórico-etimológico dos principais conceitos econômicos, dos gregos até o limiar do século XX, tendo em vista fundar as bases para uma compreensão global do fenômeno econômico, isto é, combinando a precisão das ciências exatas à maleabilidade das ciências das humanas.

\footnotetext{
${ }^{1}$ Embora haja uma série de motivos potenciais que explicam por que os Estados Alemães se juntaram ao Zollverein, estudos recentes salientam a necessidade de maior acesso ao comércio internacional. Com a crescente adesão ao Zollverein sob a liderança da Prússia, alguns Estados, sobretudo ao sul da Alemanha, temiam ficar isolados e perder, assim, o acesso à costa do Mar do Norte e os ganhos advindos disso. Ademais, os proventos gerados pela união aduaneira não foram imediatos. Nos seus primeiros oito anos de operação, o Zollverein não gerou significativo ganho econômico, já que não conseguiu promover a rápida industrialização dos Estados participantes, nem afetou fundamentalmente a dinâmica regional que caracterizava então o avanço das forças produtivas alemãs (Dumke, 1991; Lee, 1988).
} 
Desafortunadamente, não há no Brasil produção expressiva de estudos sobre o pensamento econômico alemão do século XX. Por isso, uma contribuição deste artigo é, de certa forma, lançar luz sobre alguns temas relevantes para a história do pensamento econômico contemporâneo. A princípio, delineia-se o processo de implantação do Zollverein nos domínios alemães e como isso acarretou a integração econômica e, em seguida, a unificação monetária. Destaca-se, outrossim, como o sistema de transporte ferroviário foi fundamental para articular os mercados e concretizar aquilo que List denomina unidade das forças produtivas. Adiante, ressaltam-se os esforços dos intelectuais reunidos na Friedrich List-Gesellschaft para a divulgação do pensamento de List, bem como para a proposição de soluções factíveis para reverter os efeitos negativos da crise de 1929 em solo alemão, concedendo-se especial atenção às conferências promovidas por essa entidade. Na terceira seção, discute-se a concepção de Anschauliche Theorie (Teoria intuitiva) de Edgar Salin, bem como o entendimento de Friedrich Gottl-Ottlilienfeld e Arthur Spiethoff sobre uma teoria geral da economia. Por fim, salientam-se as contribuições da List-Gesellschaft (LG) quanto ao esclarecimento de questões fundamentais sobre união aduaneira.

\section{O Zollverein e a integração econômica dos Estados Alemães}

List nasceu a 6 de agosto de 1789, em Reutlingen, Stuttgart. Após distinguir-se como burocrata, foi nomeado, em 1816, primeiro Professor de Administração e Política (Staatspraxis und Staatswissenschaft) na Universidade de Tübingen (Levi-Faur, 2012). Tornou-se secretário consulente da Deutsche Handels- und Gewerbeverein (Associação Alemã da Indústria e Comércio) e, em seguida, Deputado na Assembleia Legislativa de Württemberg, onde atuou ativamente em prol da integração econômica dos Estados Alemães. Seus artigos da época constituem provas irrecorríveis de que ele foi um dos principais idealizadores do Zollverein, ao propor a união aduaneira sob regência de um parlamento comum (Daastøl, 2016). Em seu entendimento, o Zollverein deveria unir uma nação historicamente dividida, uma vez que a confluência dos interesses econômicos particulares serviria de elo à instituição de um sentimento nacional, capaz de suprimir todos os obstáculos ao tráfico interno. Referindo-se aos inúmeros portos de alfầndegas espalhados pela Alemanha, ressalta List que para ir de Hamburgo à Áustria, ou de Berlim à Suíça, contavam-se dez 
aduanas e dez portagens, que além de dificultar o comércio, oneravam sobremodo o preço final das mercadorias (List, [1819] 1850a; [1846] 1850c).

Um ano antes de List elaborar sua petição enfatizando a necessidade de abolir os direitos aduaneiros internos na Alemanha, a Prússia tinha empreendido reforma drástica em seu próprio sistema tarifário, embora visasse unificar apenas as aduanas dos territórios estritamente prussianos, em vez de promover a união de todas as aduanas espalhadas ao longo do território alemão (Henderson, 1975; Hallerberg; Snyder, 1995). Nesse ínterim, outros Estados alemães, especialmente no sul, começaram a negociar acordos comerciais entre si.Após anos de atividade política e negociações articuladas, muitas vezes sem êxito da parte de List e seu grupo, Baviera e Württemberg consentiram em formar união aduaneira em 1827. Pouco depois, Hesse-Darmstadt concordou em aderir ao sistema prussiano, em 1828. Nesse mesmo ano, a maioria dos Estados do centro da Alemanha fundou a União Comercial da Alemanha Central (Mitteldeutscher Handelsverein), a qual foi deliberadamente criada para ser rival da união aduaneira formada entre Prússia e Hesse-Darmstadt. Em maio de 1833, a Prússia firmou tratado comercial com os reinos da Baviera eWürttemberg. Em seguida, persuadiu dois membros da União Comercial da Alemanha Central - Meiningen e Gotha - a permitir a construção de duas estradas prussianas através dos seus territórios, de modo a interligar a Bavária e Württemberg à Liga Prússia-Hesse-Darmstadt. Por outro lado, a Saxônia, sobretudo por motivos políticos, recusava-se a assinar qualquer tratado com a Prússia. Somente no limiar de 1834, uma Zollverein alemã foi constituída entre a Prússia, Nassau, Württemberg, Baviera, Saxônia e os Estados da Turíngia. Na verdade, estes últimos se juntaram apenas no decorrer dos dois anos que se seguiram, após a adesão de Baden, Nassau e da cidade de Frankfurt ${ }^{2}$ (Ploeckl, 2010; Thiveaud; Oliveira, 1992; Hirst, 1909).

Um excepcional avanço trazido pelo Zollverein localiza-se na padronização do sistema de moedas em uso para toda a área de livre comércio. Nas primeiras décadas do século XIX, circulava nos domínios alemães enorme quantidade de moedas de diferentes denominações, com destaque para o padrão Thaler nos estados do norte, incluindo a Prússia, e o padrão Gulden nos estados do sul e na Áustria.Visto que as taxas de cunhagem constituíam importante fonte de receita fiscal, muitos regentes não apenas relutavam em

\footnotetext{
${ }^{2}$ Durante as próximas duas décadas, Braunschweig, Luxemburgo (1842), Hannover e Oldenburg (1854) tornaram-se membros também. Na esteira da Guerra Austro-Prussiana de 1866, a Prússia forçou mudanças consideráveis na estrutura da união aduaneira, e, após a fundação do Império Alemão, em 1871, o Zollverein tornou-se parte fundamental de sua organização político-econômica (Ploeckl, 2010).
} 
sacrificar sua soberania em questões monetárias, mas também se mostravam bastante receosos em conceder autonomia aos bancos privados. Em 1837, Luís II da Baviera convidou o Reino de Württemberg, os grão-ducados de Hesse e Baden, os ducados de Nassau e a cidade livre de Frankfurt para examinar conjuntamente a situação monetária da Alemanha Central e do Sul. Esses seis estados fundaram uma Münzverein (União Monetária) e assinaram duas convenções em Munique, chancelando sua decisão de adotar um florin comum como unidade de conta e cunhagem. A união foi logo fortalecida pela adesão do ducado de Meiningen, em 8 de junho de 1838 e pelo principado de Schwarzburg-Rudolfstadt, em 11 de maio de 1839. Por outro lado, a Prússia, ciente tanto da vantagem obtida pelos outros estados alemães, quanto do perigo comercial, monetário e político que essa união representava para suas próprias intenções açambarcadoras, reuniu seus vizinhos e reconheceu convencionalmente a comunidade monetária que já existia em seus domínios e se baseava no Thaler, encontrando adeptos no reino da Saxônia, no eleitorado de Hesse e nos Estados da Turíngia (Ploeckl, 2010; Thiveaud; Oliveira, 1992).

Em 1838, na Convenção da Moeda de Dresden, a emissão de um meio circulante comum foi negociada para o Zollverein como um todo. Desde então, cada estado membro teve que optar pelo Thaler (subdividido em Groschen) ou pelo Gulden (subdividido em Kreuzer) como unidade monetária básica. Com isso, não apenas se instituíram especificações precisas quanto ao conteúdo e teor dos metais, mas também foram retiradas de circulação moedas depreciadas pelo desgaste, substituíndo-as por outras de valor integral. Para promover a ideia de um sistema monetário unificado e facilitar o intercâmbio entre as áreas sob o regime de Thaler e Gulden, os estados concordaram em cunhar uma moeda comum no valor de 2 Thaler ou 31/2 Gulden com a denominação Vereinsmünze (moeda da união). A partir de então, o Thaler prussiano penetrou praticamente em todo o território alemão, ganhando aceitação inclusive nos Estados do sul, o que lhe rendeu o título de moeda comum para todos os efeitos práticos, funcionando como a moeda Zollverein, símbolo da unificação monetária interestatal ${ }^{3}$ (Holtfrerich, 1993; Thiveaud; Oliveira, 1992).

\footnotetext{
${ }^{3} \mathrm{O}$ sistema monetário alemão foi organizado com base numa moeda de prata, efetivada pelo Thaler no norte e o Florin no sul. Distorções, no entanto, ainda permaneciam devido à existência de diferentes padrões monetários em Bremen, Hamburgo, Lübeck, Lauenburg e Schleswig-Holstein. Também foram utilizadas moedas de ouro, como Pistolen, Dukaten, Friedrichsd'or e Louisd'or, mas sendo empregadas principalmente em transações comerciais de atacado e como reserva cambial (Holtfrerich, 1993).
} 
Convém frisar, todavia, que, não obstante os avanços mencionados, os proventos advindos da união aduaneira não foram imediatos. Nos seus primeiros anos de operação, o Zollverein não gerou ganho significativo. Por uma questão compreensível, os territórios a que correspondiam Hanover, Brunswick, Oldenburg, bem como os Estados de Mecklenburg e as cidades Hansa, mais inclinadas ao livre comércio, não aderiram à união aduaneira, sob a alegação de que tal expediente redundaria em obstáculos aos seus negócios. Por isso, a integração econômica de todos os Estados Alemães não poderia ser realizada plenamente em 1834, não apenas por causa das divergências políticas ainda muito latentes, mas principalmente pela existência de interesses econômicos diversos. De modo equivalente, salienta Robert W. Lee, embora os efeitos da união aduaneira não sejam insignificantes, o Zollverein não conseguiu promover a rápida industrialização dos Estados Alemães, pois até então o intercâmbio comercial não afetara fundamentalmente a dinâmica regional que marcou o desenvolvimento histórico das forças produtivas alemãs (Dumke, 1991; Lee, 1988).

Além das divisões políticas, outro fator a comprometer a integração econômica residia no fato de que boas vias de comunicação para acelerar o deslocamento de matérias-primas às fábricas, bem como para transportar os produtos manufaturados aos centros consumidores, eram praticamente inexistentes na Europa Central, nas primeiras décadas do século XIX. Nesse sentido, outra grande contribuição de List no que diz respeito à integração econômica e à superação da fragmentação política dos Estados Alemães foi ter ressaltado a importância do transporte ferroviário (Eisenbahn-Dampfwagentransport) no que concerne à efetivação daquilo que denominou "unidade das forças produtivas nacionais". De acordo com o economista suábio, um sistema de transporte eficiente como o ferroviário pode encurtar distâncias e, ao mesmo tempo, fazer com que cada distrito ou província possa transportar seus excedentes a todas as outras regiões, mesmo às mais distantes e, em troca, receber a produção destas últimas. Por isso, um dos efeitos mais significativos da expansão das redes ferroviárias seria a eliminação das barreiras comerciais inter-regionais ainda existentes e, assim, promover de fato um padrão muito diferente da industrialização local e especialização econômica regional (DAastøl, 2011; Lee, 1988; List, [1841] 1983).

Em seu jornal especializado em estradas de ferro (Eisenbahnjournal), List argumentou que as rivalidades entre os Estados alemães não deveriam impedir o planejamento de uma rede ferroviária abrangendo todo o pás. Do mesmo 
modo, ressaltou que os proventos obtidos pela união aduaneira seriam grandemente aumentados por meio do melhoramento da comunicação.Dentre os benefícios das ferrovias, List destaca a imensa possibilidade de difusão do conhecimento técnico-científico e da educação em geral, a maior agilidade no movimento de matérias-primas para as fábricas e, em contrapartida, a maior prontidão no transporte de bens manufaturados para os mercados, o que impulsionaria sobremodo as forças produtivas nacionais e, assim, o desenvolvimento de todas as outras atividades econômicas. Além disso, com a expansão das redes ferroviárias, novos mercados seriam disponibilizados à indústria e à agricultura alemãs. Graças ao moderno sistema de transporte ferroviário, as fábricas situadas na Renânia e Westphalia puderam trocar suas mercadorias por produtos agrícolas das províncias agrárias situadas no leste do Elba. Quando as estradas de ferro chegaram a Hamburgo, Bremen, Stettin e Antuérpia, os produtos que antigamente tinham de ser vendidos só nos mercados locais puderam ser exportados para regiões distantes. Igualmente, foram as ferrovias que promoveram o rápido crescimento das grandes cidades do Ruhr e da Alta Silésia (Liebig, 1998; List, 1838; Curi, 2018).

Além de todas as vantagens citadas, o maior triunfo das redes ferroviárias alemãs foi, sem dúvida, ter garantido o sucesso da Zollverein, conforme List havia previsto. Por si só a abolição de muitas tarifas internas não poderia ter conferido imediatamente à indústria alemã o estímulo necessário que culminaria em seu rápido crescimento. Com o tempo, as ferrovias aproximaram as cidades e ajudaram a suprimir as rivalidades e o isolamento que tinham sido marca indelével de vários Estados e províncias durante séculos, oferecendo, assim, grande impulso à integração econômica e política.

\section{Friedrich List-Gesellschaft e a reestruturação da economia alemã nos anos 1930}

A difusão do pensamento de Friedrich List na segunda metade do século XIX ganhou impulso graças aos comentários de seus intérpretes reunidos sob insígnia da Escola Histórica Alemã. Além disso, merecem destaque a divulgação das ideias protecionistas no contexto pós-unificação da Alemanha, bem como a produção de trabalhos críticos e biográficos sobre o autor alemão. ${ }^{4}$ Posteriormente, a Friedrich List-Gesellschaft (FLG) (Sociedade Friedrich

\footnotetext{
${ }^{4}$ O primeiro grande biógrafo de List foi Ludwig Häusser (1818-1867), historiador, filólogo, político e colaborador do Allgemeinen Zeitung. Häusser recebeu autorização diretamente da família List para pro-
} 
List), fundada em 5 de setembro de 1925, em Heidelberg, por Edgar Salin, Bernhard Harms, Geoger Mayer, Friedrich Lenz, Arthur Sommer, Arthur Spiethoff, entre outros, tinha por objetivo corrigir, catalogar e reeditar a produção intelectual de List e conduzir pesquisas sobre a vida desse economista, a fim de entender em que medida o ambiente sociocultural, os eventos e personalidades importantes podem ter, direta ou indiretamente, influenciado sua formação. ${ }^{5}$ A FLG se dedicava ainda à elaboração e divulgação de pesquisas sobre História da Economia, concedendo especial atenção aos progressos na área da teoria econômica; suas conferências, por outro lado, visavam fundamentalmente promover uma fecunda troca de ideias entre economistas, cientistas políticos, homens de negócio, estadistas etc., tendo em vista melhorar os objetivos e métodos da política econômica alemã. Por causa disso, essa entidade gozava de alta reputação nacional, vindo a desempenhar papel de notável relevância no que concerne, por exemplo, à proposição de medidas factíveis para reverter os efeitos perturbadores da crise de 1929, em solo alemão ${ }^{6}$ (Proeger, 2016).

Nos dias 16 e 17 de setembro de 1931, a FLG realizou uma grande conferência em absoluto sigilo, em que se reuniram em Berlim funcionários do alto escalão do governo, professores de Economia (die Elite der akademischen Nationalökonomie), políticos, homens de negócio e banqueiros para encontrar uma forma de deter ou até mesmo provocar uma viragem na crise. Dentre os presentes nesse importante evento se destacam Hans Luther e Fritz Dreyse,

dução de material biográfico sobre o economista suábio, bem como reunir seus escritos com vistas à publicação. Devido ao Märzrevoluzion (1848-1849), os trabalhos de redação e editoração tiveram de ser suspensos, de modo que o primeiro volume veio à luz somente em 1850, com o título Friedrich List's gesammelte Schriften (Coletânea de escritos de Friedrich List), em que o autor apresenta minuciosa descrição de fatos importantes sobre a vida e obra de List (Häusser, 1850). O segundo volume, publicado no mesmo ano, reúne textos que apresentam uma exposição cronológica do pensamento de List. O terceiro e último volume é dedicado à reedição de sua obra mais completa, isto é, Das Nationale System der Politischen Oekonomie (Sistema Nacional de Economia Política, 1841).

${ }^{5}$ Entre 1927 e 1935, a FLG publicou uma coleção de dez volumes, em que foram reunidos grande número de discursos, cartas e manuscritos de List. É, sobretudo, graças a essa proeza que hoje se conhece em profundidade as ideias do economista alemão. Uma edição completa dos trabalhos de List atualmente seria inexequível devido à falta de materiais disponíveis, já que boa parte do material original se perdeu durante a Segunda Guerra Mundial (1939-1945) (Wendler, 2005, 2013).

${ }^{6}$ Com a "Grande Depressão" dos anos 1930, os bancos estadunidenses suspenderam os empréstimos ao governo alemão. A subsequente desorganização das finanças públicas e o declínio do comércio exterior resultaram numa retração de 39\% na produção industrial e no desemprego de nove milhões de trabalhadores. À depressão soma-se a instabilidade política e a impossibilidade de se formar alianças entre os principais partidos para solucionar os problemas que se tornavam cada vez mais alarmantes. Consequentemente, o ano de 1930 foi marcado pela intensificação da crise, já que o número de contratos de depósitos bancários havia despencado de modo abrupto, levando à falência muitas instituições financeiras (James, 1984; Schnabel, 2004; Noord, 2009; Eichengreen, 2012). 
respectivamente, presidente e vice-presidente do Conselho Executivo do Reichbank; Wilhelm Lautenbach, do Ministério da Economia do Reich (Reichswirtschaftsministeriums); o ex-ministro das Finanças Rudolf Hilferding; Friedrich Sämisch, presidente do Tribunal de Contas da União (Reichsrechnungshofes); altos funcionários como o Secretário Ernst Trendelenburg, responsável pelos assuntos envolvendo as receitas do Estado no Ministério da Economia; o Secretário Hans Schäffer, incumbido do tesouro imperial etc. Quanto aos professores e técnicos nos assuntos de Finanças e Economia Política, destacam-se Walter Eucken, Wilhelm Röpke, Gerhard Colm e Hans Neisser. O grupo ainda contava com a imprescindível contribuição de Eduard Heimann, Heinrich Rittershausen e Edgar Salin, o mais gabaritado no momento a reunir competência teórica e compromisso com a política econômica do novo governo $^{7}$ (Proeger, 2016; Tooze, 2003; Janssen, 2009; Kim, 1997; Borchardt; Schötz, 1991).

Uma das questões fundamentais debatidas nesse encontro foi o financiamento da criação de novos empregos pelo Reichbank, considerando-se a necessidade impreterível de retomar a produção. Nesse sentido, é digno de menção a proposta de Wilhelm Lautenbach, o conselheiro do Ministério da Economia. Em linhas gerais, sua recomendação para resolver o problema da desaceleração e do desemprego vinculava a defesa de maiores investimentos e a expansão sistemática do crédito como forma exequível de promover o incremento da produção e controlar a deflação. Outros, como o célebre reformador Gerhard Colm, consideravam importante delegar ao Estado maior participação na vida econômica, levando-se em conta o controle do câmbio e da circulação monetária; a estabilização dos preços; a criação de novos empregos e a expansão do crédito para melhorar a situação econômica geral (Proeger, 2016; Kim, 1997; Borchardt; Schötz, 1991).

Por outro lado, em seu discurso de abertura, Edgar Salin considerava desnecessária a intervenção monetária como forma de superar a profunda crise. Francamente, ele se questionava até que ponto o Reichbank podia aumen-

\footnotetext{
${ }^{7}$ A fim de acalmar os ânimos e mitigar as pressões políticas por mudanças, o então Chanceler Heinrich Brüning (1885-1970) modificou seu gabinete.Assim, em outono de 1931, o ministério liberal de Hermann Dietrich foi substituído pelo ministro da Economia, Hermann Warmbold, que, na ocasião, respondia à crescente exigência dos industriais que reclamavam uma ação governamental positiva para aliviar o estado lamentável em que se encontrava a economia alemã. Warmbold, todavia, somente uniu-se ao novo gabinete sob a condição de que Brüning considerasse seriamente um programa de crédito para a indústria, ao mesmo tempo que autorizasse ampla intervenção do Estado na economia, já que, em seu entendimento, não havia a menor possibilidade de retornar ao padrão-ouro e o livre comércio (Tooze, 2003; James, 1984).
} 
tar o crédito e em que medida apenas por meio de sua expansão poder-se-ia gerar um boom (Sonderkonjunktur) na economia. Além disso, ele via com ceticismo a possibilidade de retorno a uma política de crédito liberal tal como a que vigorou anteriormente à crise. Posteriormente, as estimativas negativas de Salin sobre o impacto da intervenção monetária foram reformuladas extensivamente e de modo ainda mais claro por Rudolf Loeb. Do mesmo modo, Hilferding julgava a continuação da prática da desproporcionalidade um mecanismo de recuperação econômica extremamente arriscado, já que se baseava no princípio da conversão da troca financeira em contas elegíveis, como letras de câmbio. Impressionado com as observações de Salin, Rudolf e Hilferding, quanto aos perigos da expansão monetária, reformadores como Wilhelm Röpke consideraram razoável diminuir, ainda que lentamente, os desdobramentos do efeito do procedimento de sucção (Sogwirkung). Desse modo, percebe-se que a discussão acerca das novas formas de ingerência estatal sobre a economia alemã recebeu significativo impulso nas conferências da FLG (Kim, 1997).

É claro que o sucesso e o prestígio da FLG não passaram despercebidos às ambições açambarcadoras do Nationalsozialismus. Essa aproximação, todavia, tornou-se inevitável na década de 1930, como resultado do aumento expressivo do número de parlamentares nazistas no Reichtag. Por causa disso, já em 15 de novembro de 1930, em Berlim, foi realizada uma reunião de cúpula da FLG, em que estavam Bernhard Harms, Erwin v. Beckerath, Karl Goeser, Friedrich Lenz, Edgar Salin, Paul Kempner (co-proprietário da Bankhaus Mendelssohn), Hans Leiter (então presidente do Reichsbank), Werner Richter (Ministério da Cultura), Friedrich Sämisch (presidente do Tribunal de Contas do Reich), entre outros. O grupo veio a ser reforçado pela presença dos professores Christian Eckert e Julius Landmann. Além dos assuntos estritamente econômicos, neste encontro, Harms provocou um debate para saber se a consideração do programa econômico nacional-socialista deveria ser objeto de discussão das ulteriores sessões da FLG (Wendler, 2005).

Nota-se nessa reunião o primeiro desentendimento interno no grupo, já que a proposta apresentada sob o título Der Nationalsozialismus, seine geistigen, wirtschaftlichen und politischen Grundlagen und Zielsetzungen (O Nacional Socialismo: seus objetivos intelectuais e seus fundamentos econômicos e políticos) não deixava claro e consensualmente definido se o escopo das próximas conferências seria a produção e a difusão de novos conhecimentos ou a análise e a discussão de um programa econômico para o Nationalsozialismus. Apesar disso, uma comissão composta por Harms, Beckerath, Lenz e Landmann elaborou um 
programa a ser apreciado pelo conselho. Nesse mesmo dia, enquanto retornava a Basel, Salin escreveu uma carta a Harms em que expressava suas preocupações quanto à decisão, em sua opinião precipitada, de considerar propícia a deliberação do programa econômico nazista, preterindo a natureza política, sociológica e ideológica desse movimento. Salin ainda ressalta a perda do foco principal da FLG, ainda que contra a vontade da maioria dos participantes, e principalmente a questão judaica. Diante de tais controvérsias, ele frisa que a presença do Nationalsozialismus implicaria necessariamente a divisão da FLG (Wendler, 2005).

O próximo grande objetivo da FLG foi organizar um grande congresso para tratar dos problemas relativos à agricultura alemã. Desde então, o elemento completamente novo foi a tentativa de se referir aos nazistas na qualidade de membros da FLG, o que agravou ainda mais o clima de insatisfação no grupo. Em carta a Adolf Hitler, de 15 de novembro de 1932, Harms comunica que a FLG realizará entre 4 e 7 de fevereiro de 1933, em Bad Oeynhause, uma conferência extraordinária em que se reunirão economistas, estadistas, políticos e empresários para discutir a política agrícola alemã no contexto da economia nacional e internacional. O propósito desse encontro seria a elaboração de projetos, visando preparar as bases e diretrizes para uma mais lucrativa e duradoura produção agrícola para a Alemanha. Harms ainda frisa que seria motivo de grande honra se seu grupo pudesse contar com a presença dos quadros do Nationalsozialismus nesse evento. Em carta a Salin de 19 novembro de 1932, Harms salienta que dos sete membros do partido por Hitler indicados, três já haviam sido convidados (Wendler, 2005).

À medida que os nazistas conquistavam mais influência política, maior pressão exerciam sobre a FLG. De fato, uma cadeia de eventos parece ter conspirado contra essa entidade. Em 6 de novembro de 1932, o Nationalsozialismus aumentou o número de seus representantes para 196 assentos parlamentares, ocupando um terço das cadeiras do Reichtag. Com efeito, diante da impossibilidade de governar, Paul von Hindenburg aceitou nomear Adolf Hitler chanceler da Alemanha, em 30 de janeiro de 1933. Não obstante a coação sobre a FLG tenha se intensificado desde então, ela ainda era suportável. No entanto, com a morte do presidente Hindenburg no ano seguinte, Hitler declarou-se Führer da Alemanha e instaurou um governo totalitário, colocando todas as instituições sob seu comando. Por essa razão, no dia 11 de agosto de 1934, a FLG cancelou formalmente seu registro de inscrição de asso- 
ciações em Stuttgart, vindo a ser dissolvida logo no ano seguinte a fim de não servir aos interesses e ambições nazistas.

\section{Salin e a teoria intuitiva (Anschaunliche Theorie) aplicada à economia}

Dentre os intelectuais da FLG, é digno de menção o professor Edgar Salin, o qual exerceu significativa influência sobre a opinião pública à época, ao empregar seu prodigioso conhecimento histórico, filosófico e econômico não apenas para aconselhar governos e homens de negócios, mas também para formar gerações de estudantes. ${ }^{8}$ Durante a juventude, Salin auferiu admirável erudição em filosofia e literatura clássica e alemã, sendo particularmente influenciado pelo célebre poeta Stephan George (1868-1933), em sua crítica à modernidade e à ideia de progresso. Durante o período de estudo na Universidade de Heidelberg, no entanto, Salin foi discípulo de Alfred Weber, irmão do famoso economista e sociólogo Max Weber, tendo sido também assistente do não menos distinguido historiador econômico Eberhard Gothein. O resultado de tão rica formação revela-se em sua diversificada e substancial produção intelectual que abrange tanto assuntos práticos quanto teóricos (Schefold, 2004).

Salin desempenhou papel de destaque no assim chamado Methodenstreit, a disputa sobre o método, protagonizada pelas escolas histórica e austríaca, e que deu origem ao fecundo debate epistemológico que atravessou gerações de intelectuais do último quartel do século XIX até as primeiras décadas do século XX. ${ }^{9}$ Uma das mais impressionantes tentativas de superar essa polêmi-

\footnotetext{
${ }^{8}$ Além da Friedrich List-Gesellschaft, Salin foi um dos fundadores, em 1954, da List-Gesellschaft (LG) como sucessora da Friedrich List-Gesellschaft, e ainda fundou a revista acadêmica, Kyklos, bem como o instituto de pesquisa Prognos.

${ }^{9}$ Em 1883, a escola histórica exercia influência predominante nas universidades da Alemanha e da Áustria, conquistando adeptos até mesmo em outras partes da Europa. Naquele ano, Carl Menger (1840-1921), com sua obra seminal sobre metodologia, conhecida como Untersuchungen über die Methode der Socialwissenschaften und der politischen Oekonomie insbesondere (Investigações sobre o método das ciências sociais e economia política em particular), lançou de Viena um ataque frontal ao historicismo. Menger identificou o erro que, em seu entendimento, confunde economias teóricas com a história da economia e, em vez disso, tentou estabelecer um lugar central à economia mediante a teoria dedutiva e abstrata. Ao contrário dos críticos modernos, Menger não descreveu a escola histórica como antiteórica. Em vez disso, ele argumentou que suas tentativas teóricas foram mal concebidas. No ano seguinte à sua publicação, Gustav Schmoller (1838-1917) respondeu publicando uma resenha crítica do Untersuchungen, e Menger contra-atacou com um livro polêmico intitulado Die Irrthümer des Historismus in der deutschen Nationalökonomie, (Os erros do historicismo na economia alemã, 1884). O debate tornou-se animado e incisivo (Hodgson, 2001).
} 
ca reside na síntese das abordagens histórica e neoclássica, proposta por Max Weber em seu projeto de uma Sozialökonomik. Grosso modo, Weber rejeitou tanto o tratamento descritivo da Escola Histórica quanto a busca de princípios universais, ao sugerir "tipos ideais" hipotéticos, destinados a servir como instrumento heurístico à compreensão de casos particulares. Enquanto discípulo de Alfred Weber, em Heidelberg, Salin destacou-se como perspicaz estudante das ciências humanas, sendo, doravante, um admirador de Max Weber, embora crítico com relação à validade epistêmica de conceitos abstratos para explicação de fenômenos sociais (Bieri, 2011).

Salin identificava na crescente abstração matemática e na busca incessante por princípios universais as causas subjacentes dos problemas epistemológicos da Economia. Ele acreditava, em vez disso, que, sendo a economia uma herdeira da filosofia antiga, da teologia escolástica e do pensamento histórico, ela constitui parte das ciências humanas. Nesse sentido, quando os economistas rejeitam o instrumental analítico das humanidades, superestimando as certezas matemáticas, eles buscam mais prestígio do que a verdade. Posicionando-se em favor de Edith Landmann, Friedrich Gundolf e o ciclo georgeano, quanto à questão posta por Max Weber sobre o juízo de valor aplicado à ciência, Salin vislumbra a possibilidade de fundar a economia sobre novo alicerce, ao propor distinção entre as teorias racional e intuitiva. Para ele, a teoria racional fornece apenas um conhecimento parcial da atividade econômica, pois, baseando-se em deduções lógicas e artificios matemáticos, desconsideram-se as peculiaridades de qualquer economia nacional, não alcançando por isso a cognição completa. Por outro lado, a teoria intuitiva (Anschauliche Theorie), integra aqueles instrumentos investigativos à ferramenta analítica das ciências humanas (História, Filologia, Sociologia, Psicologia etc.), para acomodar teorias abstratas modernas dentro do método indutivo. Tal formulação dá-se a conhecer como $\Theta \varepsilon \omega \rho i ́ \alpha$, isto é, a contemplação de um conhecimento geral sobre a complexa vida econômica, apresentando-se, então, como solução plausível à polêmica sobre o método envolvendo as escolas mencionadas (Ebener, 2009; Harada, 1997).

Salin percebeu que os "tipos ideais” de Werner Sombart (1863-1941), em contraste com a concepção de Weber, comportavam elementos não racionais que poderiam ser-lhe úteis em seu intento de fundar uma teoria econômica intuitiva. Decerto, Salin acreditava que o "caminho da cognição completa" de Sombart não é meramente histórico, mas sim teorético, basicamente, por duas razões. Em primeiro lugar, a fim de chegar às "essências", 
Sombart não apenas despreza circunstâncias acidentais, mas também busca compreender as sequências dos fatos na totalidade de suas relações racionais e irracionais. Em segundo lugar, seu propósito encontra fundamento na própria tradição alemã de que a teoria é respaldada tanto em formulações abstratas quanto na compreensão das relações concretas de contextos históricos específicos. Salin ressalta que Sombart, em sua obra Der Moderne Kapitalismus (O capitalismo moderno, 1902), propõe uma justaposição entre a teoria racional não histórica e o realismo histórico, que converge a uma teoria econômica que visa compreender o real, preservando, contudo, o lugar e o significado da história econômica em sua relação intrínseca com o mundo fenomênico. Tal consideração sobre os fatos econômicos revela sua vinculação espaço-temporal e, simultaneamente, sua particularidade cultural. É baseando-se nisso que a teoria intuitiva de Salin integra formas e campos de ação para além da restrição ao escrutínio racional, já que para ele a ciência econômica deveria ocupar-se do todo, entendido como o contexto universal da experiência, em seu ambiente histórico-institucional ${ }^{10}$ (Salin, 1924, [1927] 1987; Harada, 1997; Schefold, 2016).

Em vez de afirmações abstratas, apoiadas em provas formais, a teoria intuitiva representaria o desígnio de apreender as diferentes dimensões da economia em sua inter-relação como um todo, expresso de modo indireto por meio de analogias históricas, com vistas a integrar o modelo formalista ao descritivo-fenomênico, tal como combinados nas obras de Smith, List, Marx e Keynes. A questão posta por Landmann, Salin e, mais genericamente, pelo ciclo georgeano consistia em inquirir em que medida se explica, de fato, aquilo que está para além do âmbito racional-argumentativo da ciência positiva, especialmente em sua versão formalizada e matematizada. $\mathrm{O}$ objetivo, e também a maior dificuldade de uma teoria intuitiva, era produzir um conhecimento que excedesse os limites da abordagem estritamente mecânica e dedutiva, mas que, ao mesmo tempo, fosse capaz de revelar explicitamente a dinâmica inerente ao capitalismo moderno, tanto de uma perspectiva quantitativa quanto qualitativa, segundo uma visão global, totalizante (Salin, [1929] 2007).Tal intento havia sido perseguido anteriormente por Friedrich

\footnotetext{
${ }^{10}$ Sombart não foi apenas um escritor prolífico, mas também um dos oponentes mais vociferantes contra a aplicação excessiva do método da ciência da natureza à economia. Em vez disso, ele afirma que existe um método apropriado à investigação das ciências sociais, que lida exclusivamente com a cultura, a saber, o método da Geisteswissenschaft (ciência do espírito). O entendimento sistemático das implicações econômicas dessas normas culturalmente embutidas é precisamente o que caracteriza a economia política de Salin (Bieri, 2011).
} 
Edler von Gottl-Ottlilienfeld (1869-1958), que formulou uma Allwirtschaftslehre (Economia Universal), a constituir a Nationalökonomie, como uma abrangente teoria social expressa em uma "ciência empírica da vida econômica de todos os tempos e povos”. Em seu ponto de vista, a economia não é uma ciência claramente definida no que concerne à sua área de assunto concreto, mas pode ser entendida como componente integrador da vida cotidiana. Nesse sentido, sua estruturação constitui-se uma tarefa econômico-social combinada, em que a teoria econômica deve fundir-se à teoria sociológica (Schefold, 2004; Schönhärl, 2009; Ebener, 2010; Gottl-Ottlilienfeld, 1901, p. 131).

Arthur Spiethoff (1873-1957), por seu turno, desempenhou igual papel de destaque na polêmica concernente ao método. Após estudar economia e ciência política na Universidade de Berlim (1893-1899), adquirindo primorosa instrução sob orientação dos ilustres economistas AdolfWagner e Gustav Schmoller, assentou Spiethoff as bases de uma teoria geral da economia (Allgemeine Volkswirtschaftslehre). Em 1905, Spiethoff doutorou-se com uma tese intitulada Beiträge zur Analyse und Theorie der allgemeinen Wirtschaftskrisen (Contribuições para a análise e teoria geral das crises econômicas), em que assume o compromisso de combinar a perspectiva histórica à moderna teoria econômica desenvolvida fora da Alemanha. ${ }^{11}$ Sem dúvida, ele acreditava que o raciocínio abstrato cumpre papel imprescindível à ciência econômica, já que favorece a compreensão de certos fenômenos e princípios em sua forma pura, mediante a elaboração de modelos e conceitos analíticos que, se bem dirigidos, propiciam a compreensão de fatos essenciais. Desse modo, uma particularidade na caracterização da economia segundo Spiethoff encontra-se em sua aspiração a uma teoria, que pretende apreender o "ser permanente" dos elementos que constituem as diferentes formações econômicas independentemente das condições históricas e geográficas. No entanto, como em Salin, essa pretensão a uma teoria geral só pode servir como um auxílio à teoria historicamente mais descritiva, "realista", que seja útil para uma visão espaço-temporal da vida econômica, englobando seus aspectos institucionais ${ }^{12}$ (Spiethoff, 1932; Harada, 1997; Kurz, 2010).

\footnotetext{
${ }^{11}$ Em sua Geschichte der Volkswirtschaftslehre (História da Economia, 1923), Salin avalia o trabalho de Spiethoff sobre crises e business cycles como uma completa e perspicaz amálgama de teorias racional e histórica, em que se destaca uma formidável articulação entre fenômenos observáveis (anschaulich) e teóricos ou puros, sem que haja prejuízo no que toca à preservação da tradição histórica em sua forma essencial, ou qualquer forma de sujeição quanto à independência do pensamento genuinamente teórico (Kurz, 2010).

${ }^{12}$ Com base no viés histórico da economia nacional, tal como expresso em List, ou seja, respaldando-se na rejeição a soluções abstratas que reivindicassem igual validade para todas as circunstâncias econômicas, mas,
} 
O objetivo de Salin consistia, portanto, em combinar em uma só teoria preceitos econômicos dimanados de diferentes perspectivas analíticas, que, embora se apresentem de forma muitas vezes discrepante, são passíveis de conciliação. Decerto, Salin identificava nos economistas ortodoxos os protagonistas de um conhecimento parcial, pois de certo modo negligenciavam a diversidade da cultura humana. Nesse sentido, pode-se dizer que, de um ponto de vista estritamente teórico, seu propósito em sua Geschichte derVolkswirtschaftslehre (1923) era não apenas apontar as inconsistências do historicismo, mas também evidenciar as limitações da ortodoxia neoclássica. Nessa obra monumental, Salin ainda oferece exame crítico e abrangente acerca da História do Pensamento Econômico, dos gregos até o limiar do século XX, em que ganham relevo tanto os representantes das escolas clássica e neoclássica (Smith, Malthus, Ricardo, Pareto, Marshall) quanto os economistas históricos; particularmente, os já mencionados Werner Sombart e Max Weber. Em seu ensaio Kapitalbegriff und Kapitallehre von der Antike zu den Physiokraten (Conceito e teoria do capital desde a antiguidade até os fisiocratas, 1930), material elaborado como parte de um tratado intitulado Das Kapital in der vorklassischen Wirtschaftslehre (O capital na economia pré-clássica), Salin apresenta detalhada genealogia dos conceitos econômicos desde os pré-socráticos. Trata-se de um trabalho de inefável erudição que visa revelar não apenas o sentido hermenêutico dos conceitos, mas também indicar as causas de sua metamorfose no correr do tempo. Com base no imponente saber adquirido em história econômica e história do pensamento econômico, Salin constituiu em torno de si uma autoridade quase inquestionável em assuntos práticos e teóricos, o que explica sua importância no debate sobre a unificação dos mercados europeus (Salin, [1929] 2007; Wilhelm, 2016).

\section{List-Gesellschaft e a integração econômica europeia}

em vez disso, ancorado sobre um novo princípio teórico, restrito a um determinado momento e localidade, Spiethoff delimita cada "estilo econômico" (Wirtschaftsstil) a um período e região específicos, caracterizado pelo que denominou "coexistência econômica" (wirtschaftliches Zusammenleben). Em seu entendimento, uma teoria válida para um único "estilo de economia" particular, dever-se-ia chamar Economia Geral (Allgemeine Volkswirtschaftslehre), o que evidencia notável influência da tradição econômica alemã, já que do ponto de vista da Escola Histórica, a teoria em princípio possui validade restrita ao espaço e ao tempo, de modo que até mesmo a teoria geral é válida em apenas um cenário cronológico. Spiethoff reverencia, assim, o conceito de teoria intuitiva, tomando emprestado tanto o nome quanto o arcabouço teórico de Salin e Sombart sobre formações econômicas em períodos históricos distintos. Além disso, ele diz que tal modelo teórico é obtido mediante a análise e consideração de muitos fenômenos parciais da coexistência econômica, o que comprova a aplicação do método indutivo, visando obter uma imagem teórica transcrita da realidade (Harada, 1997). 
Desde sua fundação, em 1954, a List-Gesellschaft (LG) se dedica à proposição de soluções práticas para problemas econômicos e sociopolíticos, tornando os resultados de suas pesquisas e conferências utilizáveis para se pensar as grandes questões contemporâneas ${ }^{13}$ (Wendler, 2013). Com esse propósito, ela desempenhou papel de destaque no debate em favor da integração econômica europeia. De fato, os anos que sucederam a criação da LG foram marcados por notável produção monográfica, bem como por uma série de conferências em que se discutiram em profundidade questões como integração plena e parcial, política de preços, oferta de trabalho, extensão do mercado, métodos e custos de exploração do carvão e produção do aço etc. (Erb; Rogge, 1958). Antes de Salin e seu grupo, no entanto, estudiosos do comércio internacional e da união aduaneira, como Jacob Viner e James Edward Meade, já haviam explicitado em nível conceitual as vantagens inerentes à integração econômica. Direta ou indiretamente, eles reconheciam a validade do postulado listiano de que uniões e tratados comerciais que envolvem beneficios mútuos são meios eficazes de estreitar as relações entre as diferentes nações. O Zollverein foi considerado, por causa disso, um importante acordo de livre comércio e um paradigma a ser seguido. Por seu intermédio, pela primeira vez, Estados politicamente independentes eliminaram barreiras comerciais entre si, conferindo autoridade delegada a um corpo superior. Por conseguinte, ao longo das negociações para instaurar uma área de livre comércio na Europa, inúmeras referências foram feitas ao Zollverein. Na verdade, quase todas as especulações sobre a origem, natureza e consequências políticas e econômicas da unificação das tarifas tendiam de alguma forma a se basear na experiência alemã. Não é de admirar que, desde o início, a Alemanha já era considerada modelo à integração europeia (Viner, 1950; De Cecco, 1999; Dumke, 1984; Hallstein, 1963; Salin, 1960).

As conferências da LG foram, outrossim, determinantes no que concerne à avaliação da exequibilidade da união aduaneira europeia.Todavia, em vez de lançar mão da designação Comunidade Econômica Europeia (Europäische Wirtschaftsgemeinschaft), preferiu-se o termo Kerneuropa, com a intenção de inserir Alemanha no âmago do debate sobre a integração, bem como chamar atenção para o fato de ser a Europa um continente, e não uma espécie de

\footnotetext{
${ }^{13}$ Dentre as instituições que financiaram prodigamente a List-Gesellschaft (LG), merece destaque não apenas o Fundo Nacional Suíço e a Fundação Ford, mas principalmente o Instituto Israelita Flak. Além da questão energética, uma das especialidades de Salin, a LG incumbiu-se de elaborar estudo minucioso sobre a importância das organizações coletivas, como o Histadrut, Kibbutz e o Moshav para o desenvolvimento social, cultural e, sobretudo, econômico do recém-fundado Estado de Israel (Wilhelm, 2016).
} 
apêndice da Ásia. Nesse sentido, Salin emprega estrategicamente o vocábulo Kern em sua retórica, significando tanto a ideia de "cerne" e "centro", quanto "embrião", “origem”, "princípio","base”, “começo” etc. Desse modo, em uma brochura intitulada Friedrich List. Kerneuropa und die Freihandelzone: Zwei Reden zur Europäischen Politik (Friedrich List. Núcleo da Europa e a área de livre comércio: dois discursos sobre a política europeia, 1960), Salin faz referência explícita à experiência do Zollverein e, simultaneamente, assenta as bases da futura União Europeia, visto que, em seu entendimento, uma área de livre comércio no interior de um território aduaneiro único (einheitlichen Zollgebiet) contemplaria a circulação não apenas de mercadorias, mas também de pessoas, capitais e serviços ${ }^{14}$ (Salin, 1960).

Conforme Salin, a Comunidade Econômica Europeia (CEE) não é senão o que List havia concebido como União Aduaneira Europeia (Europäischer Zollverein) ou aliança continental. Esta, todavia, tal como o Zollverein, não seria um fim em si mesmo, mas apenas uma etapa intermediária com vistas à instituição de uma economia mundial ou cosmopolítica. Isso porque uma área de livre comércio implica tanto a supressão de todas as barreiras comerciais internas (Handelsbeschränkungen) quanto o estabelecimento de restrições à entrada de mercadorias provenientes do exterior (Salin, 1960). Salin recorda que List, baseando-se na História, ilustra tal paradoxo ressaltando a experiência da Grã-Bretanha, a qual, por meio da união dos três reinos, Inglaterra, Escócia e Irlanda, revelou ao mundo como funcionam, na prática, os mecanismos implícitos à política econômica de um território aduaneiro unificado. Para Salin, portanto, o Zollverein europeu seria somente um estágio intermediário (Zwischenzustand), visando ao aperfeiçoamento das instituições europeias, bem como seu fortalecimento econômico. Para levar a termo esses propósitos, no entanto, era mister vencer a resistência, gerada pela desconfiança e, sobretudo, pelo trauma causado pelas duas grandes guerras (Salin, 1960).

Tal como List no caso da Alemanha, Salin apoia-se na História para assentar as bases da futura confederação europeia. Em sua visão, a Europa é

\footnotetext{
${ }^{14}$ Conceitualmente, os teóricos da List-Gesellschaft, como Gottfried Erb e Peter Rogge, definem esse fenômeno como integração plena (Vollintegration), o qual se caracteriza pela uniformização dos pedágios de trânsito, políticas sociais, normas jurídicas e financeiras, bem como pelo estabelecimento de maior segurança quanto à oferta de bens, capitais, serviços etc. A integração é, portanto, algo completamente diferente do que a mera interação de mercados, pois ela cria de modo efetivo maior unificação político-econômica (Erb; Rogge, 1958). Hebert Giersch, por exemplo, definia integração como uma articulação interindependente dos mercados em uma área de comércio comum, ou seja, isenta de fronteiras internacionais que impedissem as relações políticas e econômicas entre os países envolvidos (ver o discurso de Hebert Giersch (apud Bochud, 1965) na sessão “Generaldiskussion zu den Themen:Erhöhung des Goldpreise? und Flexible Wechselkurse?: Marktintegration, Wechselkurs und Standortstruktur”).
} 
essencialmente um fenômeno histórico que deriva sua singularidade cultural da mistura de elementos germânicos e latinos, ao passo que funda sua unidade política no Império de Carlos Magno, o qual não era nem francês nem alemão, mas sim europeu, situado no coração da Europa (Salin, 1960). De acordo com Salin, desde a fragmentação do Império Carolíngio, a Europa encontra-se dividida. Somente com a instituição da Comunidade Econômica Europeia ela caminharia novamente no sentido de restabelecer diplomaticamente os alicerces de sua completa unidade. Além dos intrincados problemas políticos e econômicos, outra questão a ocupar o pensamento de Salin era se os habitantes da Kerneuropa, ou seja, alemães, franceses, belgas, holandeses, luxemburgueses e italianos se reconheciam, de fato, como europeus. Salin chama a atenção, assim, para a necessidade de se construir uma nova identidade cultural supranacional como forma de estreitar os laços de solidariedade entre esses povos, os quais, de certo modo, ainda ressentiam as lembranças perturbadoras da recente guerra (Salin, 1960).

Salin estava convicto de que não haveria alternativa mais viável para impulsionar as economias dos Estados europeus do que a aposta máxima da união aduaneira europeia. A plena efetivação desse objetivo, todavia, levantava uma série de questões econômicas importantes, como a uniformização monetária, a qual constituía elemento fundamental à plena integração econômica. ${ }^{15}$ Novamente, Salin recorreu a experiência histórica alemã para mostrar como a padronização monetária instaurada pelo Mark Bank de Hamburgo, com a implementação do Deutsche Mark, provou-se favorável à promoção do comércio e à estabilidade econômica. ${ }^{16}$ Ele acreditava que a introdução de um goldflorin europeu seria de grande benefício para fundar a aliança continental, já que a estabilidade do dinheiro e a preservação de seu poder de compra criariam uma confiabilidade que proporciona segurança em um mundo suscetível a ciclos inflacionários. ${ }^{17}$ Salin argumentava que a equivalência pecu-

\footnotetext{
${ }^{15}$ Em seu livro Preispolitik im Teilintegrierten Markt (A política de preços no mercado semi-integrado), Erb e Rogge já afirmavam que a integração plena não geraria qualquer problema particular à política de preços no que se refere à economia nacional. De fato, eles reconhecem que possíveis incompreensões desse ponto decorrem da forma como o conceito de integração é empregado. Na prática, ele nada mais é do que a criação de um mercado comum a integrar os traços característicos específicos dos mercados internos das economias nacionais individuais (Bochud, 1965; Erb; Rogge, 1958).

${ }^{16}$ Com a fundação do Reich, em 1871, duas medidas de política monetária consolidaram a unificação do espaço econômico alemão: a lei monetária de 1873, que instituiu o marco atrelado ao padrão-ouro, e a criação do Reichbank, em 1875, que funcionou como banco central, consolidando suas reservas a partir das indenizações de guerra pagas pela França. (Curi, 2018).

${ }^{17}$ Urge lembrar que a decisão de adotar o Euro como moeda única foi tomada num momento em que os movimentos de capital foram liberalizados. A iniciativa foi a forma encontrada para evitar a especulação
} 
niária certamente ofereceria maior garantia de unidade contra as tendências de desintegração melhor do que qualquer acordo econômico. Isso porque, ao facilitar a circulação de mercadorias e, por conseguinte, o intercâmbio comercial, a moeda única (einheitswährung) promoveria a prosperidade de todos os envolvidos. ${ }^{18}$

Cumpre observar que a abolição das aduanas e dos direitos de portagem tem como implicação necessária uma transformação fundamental ao nível das relações de concorrência. Na prática, se a supressão das tarifas internas cria, de um lado, novas oportunidades de mercado e de ampliação de postos de trabalho, favorecendo o crescimento de algumas empresas, ao abrir-lhes novas oportunidades de mercado, por outro lado, é inegável que essa nova configuração das forças políticas e econômicas aumenta, com efeito, a concorrência das importações, ocasionando a falência dos negócios obsoletos. Isso pode até parecer razoável do mero ponto de vista do consumidor, mas acarreta diversos problemas socioeconômicos. Quanto a esse dilema, Salin não vislumbrava solução imediata. Ele acreditava que o resultado final do desencadeamento desse processo dependeria do tamanho do mercado comum e do consequente aumento da produtividade, o que acarretaria maior oferta de bens e, por conseguinte, a generalização da melhoria do padrão de vida a todos os níveis sociais (Salin, 1960).

Decerto, conquanto List reconheça as vantagens gerais do livre comércio, ele preferia limitar seu impacto a países com níveis semelhantes de desenvolvimento. Em nações desprovidas de sólida força produtiva, cujo mercado manufatureiro está exposto à livre concorrência por parte de uma nação já dotada

\footnotetext{
sobre as taxas de câmbio, pois grandes flutuações ameaçariam o mercado integrado de bens e serviços. A questão não muito clara à época sobre a lógica de adotar a moeda única é que o sistema bancário se torna, assim, cada vez mais pan-europeu, com bancos operando acima das fronteiras nacionais e sendo propriedade de acionistas de muitos países (Wyplosz, 2009).

${ }^{18}$ Nos dias 5 e 6 de março 1965, em Frankfurt am Main, a LG realizou uma conferência, organizada por Salin, Hans C. Boden, Franz Etzel, Hand Moeller, em que se reuniram cerca de sessenta especialistas em finanças e administração pública, banqueiros e economistas de oito diferentes países dos continentes europeu e americano para discutir o tema da política monetária. Nesse evento intitulado Fundamentale Fragen künftiger Wärungspolitik (Questões fundamentais da política monetária futura), os participantes refletiram basicamente sobre três tópicos essenciais: (i) Erhöhung des Goldpreises? (Elevação do preço do ouro?) (ii) Flexibel Wechselkurse? (Taxas de câmbio flexíveis?) (iii) Europäische Währungsunion? (União Monetária Europeia?). Em seu discurso intitulado II Thesen zur Frage der Europäischen Währungsunion (II Teses sobre a questão da união monetária europeia), Salin sustentou que o êxito da CEE dependeria não apenas da unificação dos direitos aduaneiros ou do estabelecimento de uma unidade nuclear de conta europeia, mas, principalmente, da instituição de uma moeda comum. Ele afirma também que a união monetária europeia não seria um postulado utópico, mas uma ferramenta útil cuja validade geral seria verificada historicamente, sendo, portanto, oportuna a deliberação sobre a formação da futura política monetária (Bochud, 1965).
} 
de supremacia manufatureira, List observa que, amiúde, o valor das importações ultrapassa sobremodo o valor dos produtos exportados, o que por vezes ocasiona contínua exportação de espécies, podendo gerar até contração na economia. A esse respeito, List é enfático ao afirmar que, as exportações de lingotes de ouro e prata, por minarem o sistema de circulação de papel-moeda, necessariamente levam à ruína do crédito dos bancos, e consequentemente a revoluções gerais nos preços da propriedade da terra e dos bens em circulação. Por outro lado, a destruição e as convulsões do comércio e do sistema de crédito, somadas às reduções de consumo, acarretam danos para o bem-estar dos indivíduos, deixando atrás de si consequências sociais desastrosas (List, [1841] 1983; Wendler, 2013, 2014, 2017).

Atualmente, além da imigração crescente, outras razões que levam o Reino Unido a abandonar o bloco europeu localizam-se no lento crescimento e na parca competitividade econômica de alguns dos membros da União Europeia (UE). Isso, em certa medida, faz recordar um dos argumentos mais importantes desenvolvido por List a respeito do livre comércio. Como exposto antes, o economista alemão acreditava que o comércio livre e irrestrito entre diferentes nações, reconhecendo todas elas as mesmas condições de direito entre si e renunciando aos próprios interesses, só pode ser realizado com sucesso se elas tiverem atingido mais ou menos o mesmo grau de indústria e civilização, de cultura política e poder. Somente sob tais circunstâncias essa união favorece o crescimento de todos. Caso contrário, as nações em estágio defasado de desenvolvimento terão em breve tempo reduzidas suas já precárias forças produtivas. Consequentemente, sua produção e seu poder de consumo serão escassos. Decerto, um sistema continental eficaz, diferentemente do que tem acontecido com a UE, só pode ter êxito se tiver como objetivo e concretizar uma participação igual nas vantagens resultantes desse pacto, o que não tem acontecido até agora, uma vez que o rápido crescimento econômico de alguns dos seus membros resulta da importação de capital, e não do aprimoramento e ampliação de investimentos em infraestrutura, transporte, produção de energia e gestão de recursos hídricos, condictio sine qua non de todo o desenvolvimento econômico (List, [1839] 1850b, [1841] 1983).

\section{Considerações finais}

$\mathrm{O}$ artigo buscou ressaltar a influência do pensamento de List no século $\mathrm{XX}$, colocando em evidência como seus esforços em prol do Zollverein foram 
posteriormente retomados e ressignificados a fim de servir de norte para pensar a integração econômica europeia. Na década de 1920, a Friedrich List- Gesellschaft, entidade fundada a princípio para catalogar e editar a produção intelectual de List, veio a auferir notável prestígio, ao propor de medidas factíveis para reverter os efeitos nefastos da grande depressão em solo alemão. A List-Gesellschaft, por sua vez, foi de vital importância para o esclarecimento das vantagens inerentes à implantação da área de livre comércio na Europa. A seção sobre o debate em torno do método e da teoria econômica visou mostrar como Salin e outros membros da FLG compreendiam a economia de um ponto de vista holístico, percepção que configurava notável avanço à época. Por outro lado, a ênfase dada ao Zollverein justifica-se por este ter sido tomado como modelo de integração econômica a ser seguido. Salin, por exemplo, apresentava List como um dos precursores da União Europeia, ao conceber a ideia de Europäische Zollverein, (União Aduaneira dos Estados Europeus), embora não tenha levado devidamente em consideração sob quais circunstâncias List admite que a supressão das barreiras comerciais cria um estado de coisas que beneficia a todos.

Com as crises que se sucederam aos anos 2007-2008, juntamente com a elevação da taxa de desemprego, cresceram os movimentos ultranacionalistas. Esses grupos têm encontrado grande recepção e se fortalecido politicamente em diversos países da União Europeia. As crises, as incertezas, o terrorismos etc. têm gerado o fenômeno a que se denomina "euroceticismo". Hoje a União Europeia enfrenta um dos seus maiores desafios, isto é, impedir que a comunidade se fragmente. Em 2016, um dos seus mais importantes filiados, a saber, o Reino Unido, declarou que sairia do bloco, o que pode ter implicações econômicas muito negativas, pois a economia do Reino Unido é uma das maiores do mundo e vários países da Europa dependem dela. Com isso, é provável que a União Europeia fique menos atraente para investimentos e negócios. Ainda é muito cedo para fazer prognósticos acerca do futuro da União Europeia. O que se percebe é que até agora tem se confirmado a previsão de List, que, como visto, afirmava que o livre comércio, em se tratando de países com grandes diferenças nos níveis de desenvolvimento das forças produtivas, está certamente fadado a malograr. Tudo isso mostra nitidamente ser este um momento crucial para se repensar o futuro da Europa. 


\section{Referências}

BIERI, D. S. Intuitive economics: on the role of power and knowledge in post-crisis economics. 2011. Disponível em: <http://david-bieri.com/docs/IntuitiveEcon_Bieri.pdf>. Acesso em: 2 fev. 2019.

BOCHUD, F. (Org.). Fundamentale Frage Künftiger Waerungspolitik. Basel; Tuebingen: Kyklos-Verlag (Veroeffentlichungen der List Gesellschaft), 1965.

BORCHARDT, K.; SCHÖTZ, H.-O. Wirtschaftspolitik in der Krise: Die Geheimkonferenz der Friedrich-List-Gesellschaft im Setember 1931 über Möglichkeiten und Folgen einer Kreditausweitung. Aus Monografien der List-Gesellschaft Neue Folge, Band 13, p. 1-6, 1991.

CHANG, H.-J. Kicking away the ladder: development strategy in historical perspective. London: Anthem Press, 2007.

CURI, L. F. B. Nationalökonomie nos trópicos: pensamento econômico alemão no Brasil (1889-1945). São Paulo: USP, 2018 (Tese de Doutorado em História da USP).

DAASTØL,A. M. Friedrich List's heart, wit and will: mental capital as the productive force of progress. Efurt: Universität Erfurt, 2011 (Tese de Doutorado em Economia da Universität Erfurt).

DAASTØL,A. M. Friedrich List: the international dynamics of mindpower. In: REINERT, E. S; GHOSH, J.; KATTEL, R. Handbook of alternative theories of economic development. Cheltenham:Eward Elgar Publiching, p. 87-106, 2016.

DE CECCO, M. L'oro di Europa: monete, economia e politische nei nuovi scenari mondiali. Roma: Donzelli Editore, 1999.

DUMKE, R. H. Tariffs and market structure: the german zollverein as a model for economic integration. In: LEE, R.W. (Org.). German industry and german industrialisation: essays in german economic and business history in the nineteenth and twentieth centuries. London: Routledge, 1991.

EBENER, A. Ökonomie als Geisteswissenschaft? Grundzüge der Erklären- 
Verstehen-Kontroverse in den deutschen Wirtschaftswissenschaft. Überarbeitete Fassung des Beitrags zur Jahrestagung des VfS-Ausschusses für die Geschichte der Wirtschaftswissenschaften in Stuttgart-Hohenheim, n. 27-29, p. 1-34, 2010.

EICHENGREEN, B. A globalização do capital: uma história do sistema monetário internacional. São Paulo: Editora 34, 2012.

ERB, G.; ROGGE, P. Preispolitik im Teilintegrierten Markt. Basel; Tuebingen: Kyklos-Verlag (Veroeffentlichungen der List Gesellschaft), 1958.

FURNISS, H. Life of Frieddrich List, and selections from his writings by Margaret E. Hirst and F.W. Hirst. The Economic Journal, v. 19, n. 75, p. 432-435, 1909.

GOTTL-OTTLILIENFELD, F. von. Die Herrschaft des Wortes: Untersuchungen zur Kritik des nationalökonomischen Denkens. Jena:Verlag von Gustav Fischer, 1901.

HALLERBERG, M.; WEBER, K. German unification 1815-1871 and its relevance for integration theory. European Integration, v. 24, n. 1, p. 1-21, 2002.

HARADA, T.Two developments of the concept of Anschauliche Theorie (Concrete Theory) in Germany and Japan. In: KOSLOWSKI, P. (Org.). Methodology of the Social Sciences, Ethics, and Economics in the Newer Historical School. From Max Weber and Rickert to Sombart and Rothacker. Berlim: Springer-Verlag, p. 375-411, 1997.

HENDERSON, W. O. The rise of german industrial power 1834-1914. California: University of California Press, 1975.

HIRST, M.E. Life of Friedrich List and selections from his writings. London: Smith, Elder \& CO., 1909.

HODGSON. G. M. How economics forgot history: the problem of historical specifity in social science. Londres; Nova York: Routledge, 2001.

HOLTFRERICH, C.-L. Did monetary unification precede or follow political 
unification of Germany in the 19th century? European Economic Review, n. 37, p. 518-524, 1993.

JAMES, H. The causes of the german banking crisis of 1931. The Economic History Review, v. 37, n. 1, p. 68-87, 1984.

JANSSEN, H. Zwischen Historismus und Neoklassik: Alexander Ruestow und die Krise in der deutschen Volkswirtschaftslehre. Türingen: Hamburgischer Weltwirtschafts Institut, 2009.

KIM, H.-L. Industrie, Staat und Wirtschatspolitik: Die Konjunkturpolitische Diskussion in der Endphase der Weimar Republik 1930-1932/33. Berlim: Duncker \& Humblot, 1997.

KURZ, H. D. The beat of economic heart. Joseph Schumpeter and Arthur Spiethoff on business cycles. Munich Personal RePEc Archive (MPRA), n. 20429, p. 1-33, 2010.

LEE, R. W. Economic development and the state in nineteenth century Germany. The Economic History Review, New Series, v. 41, n. 3, p. 346-367, 1988.

LEVI-FAUR, D. Friedrich List and the political economy of the nation-state. Review of International Political Economy, v. 4, n. 1, p. 157-178, 2012.

LIEBIG, M. Friedrich List and the american system of political economy. EIR News Service Inc., v. 25, n. 12, p. 25-29, 1998.

LIST, F. Aufsätze in Sache des Handesvereins (1819). In: HAUESSER, L. (Org.). Friedrich List's gesammelte Schriften (Zweiter Theil). Band II. Stuttgard; Tuebingen: F. G. Cotta'scherVerlag, p. 15-62, 1850a.

LIST, F. Das deutsche National-Transport-System in volks-und staatswirthschaftlicher Beziehung beleuchtet. Altona; Leipizig: Hammerich Verlag, 1838.

LIST, F. Die Freiheit und die Beschränkungen des auswaertigen Handels aus dem historischen Gesichtspunkt beleuchtet (1839) In: HAUSSER, L.(Org.). Friedrich List' gesammlte Schriften (Zweiter Theil). Band II. Stuttgart; Tübingen: F. G. Cotta'scherVerlag, p. 63-100, 1850b. 
LIST, F. Die politische oekonomische Nationalheit der Deutschen (1846). In: HAUSSER, L (Org.). Friedrich List' gesammlte Schriften (ZweiterTheil). Band II. Stuttgart;Tuebingen: F. G. Cotta’scherVerlag, p. 367-434, 1850c.

LIST, F. Sistema nacional de economia política (1841). São Paulo:Abril Cultural, 1983.

LIST, F.Vorschläge, Deutschlands künftigen Handel betreffend. Allgemeiner Anzeiger der Deutschen, n. 209-211, p. 2209-2216, 1815.

NOORD, P. v. Economic Crisis in Europe: Causes, Consequences and Responses. European Economy, n. 7, p. 1-90, 2009.

PLOECKL, FThe Zollverein and the formation of a customs union. Discussion Papers in Economic and Social History, n. 84, p. 1-40, 2010.

PROEGER, T. Eine Ideengeschichtliche Analyse der Kritik deutscher Oekonomen an Geldmengenexpansionen 1929-1933. Sofia (Sonderforschungsgruppe Institutionenanalyse), v. 16, n. 2, p. 1-92, 2016.

SALIN, E. Geschichte der Volkswirtschaftslehre (1929). Berlin: Springer Verlag, 2007.

SALIN, E. Friedrich List. Kerneuropa und die Freihandelzone: Zwei Reden zur europaeischen Politik. Tuebingen:J. C. B. Mohr (Paul Siebeck), 1960.

SALIN, E. Hochkapitalismus. Eine Studie überWerner Sombart, die deutsche Volkswirtschaftslehre und das Wirtschaftssystem der Gegenwart (1927). In: BROCKE, B. (Org.). Sombarts Moderner Kapitalismus. Materialien zur Kritik und Rezeption. München, p. 161-195, 1987.

SALIN, E. Kapitalbegriff Und Kapitallehre Von Der Antike Zu Den Physiokraten. Vierteljahrschrift Für Sozial - Und Wirtschaftsgeschichte, JSTOR, v. 23, n. 4, p. 401-440, 1930.

SCHEFOLD, B. Edgar Salin and his concept of "Anschaunliche Theorie" ("Intuitive Theorie") during the interwar period. Series: Economic Thought and Policy in the Interwar Period, n. 46, p. 1-16, 2004. 
SCHEFOLD, B. Great economic thinkers from Antiquity to the Historical School. London: Routledge, 2016.

SCHEFOLD, B. Great economic thinkers from the Classicals to the Moderns. Londres; Nova York: Routledge, 2017.

SCHÖNHÄRL, K. Wissen und Visionen:Theorie und Politik der Ökonomen im Stefan George-Kreis. Berlin:Akademie Verlag GmbH, 2009.

SCHNABEL, I.The German Twin Crisis of 1931. The Journal of Economic History, Vol. 64, n. 3, p. 822-871, 2004

SCHMIDT, K.-H. Friedrich List's striving for economic integration and development. In: BACKHAUS, J. G. (Org.). Handbook of the history of economic thought: insights on the founders of modern economics. London: Springer, p. 351-368, 2012.

SNYDER. L. L. Roots of german nationalism. Bloomington: Indiana University Press, 1978.

SPIETHOFF, A. Die Allgemeine Volkswirtschaftslehre als geschichtliche Theorie. Die Wirtschaftsstile. Schmollers Jahrbuch für Gesetzgebung, Verwaltung und Volkswirtschaft im Deutschen Reiche, v. 56, n. 2, p. 51-84, 1932.

THIVEAUD; J.-M.; OLIVEIRA, M. de. Les unions monétaires en Europe au XIXe siècle. Revue d'Économie Financière, v. 2, n. 1, p. 161-172, 1992.

TOOZE,A.J. Statistics and the german state, 1900-1945: the making of modern economic knowledge. Cambridge: Cambridge University Press, 2003.

VINER, J. The customs union issue. Nova York: Carnegie Endowment for international Peace, 1950.

WENDLER, E. Die Friedrich-List-Gesellschaft (FLG) und der Nationalsozialismus. List Forum fürWirtschafts- und Finanzpolitik, v. 31, n. 3, p. 197-214, 2005. 
WENDLER, E. Friedrich List (1789-1846): a visionary economist with social responsibility. Nova York: Springer, 2013.

WENDLER, E. Friedrich List im Zeitalter der Globalisierung: Eine Wiederendeckung. Reutlingen: Springer Gabler, 2014.

WENDLER, E. Nie war er so wert wie heute! Die ökonomischen Lehren von Friedrich List. Bdvb aktuell (Aus Wirtschaft und Gesellschaft): Perspektiven für Europa. Nur wo Licht ist, ist auch Schatten, n. 136, p. 24-30, 2017.

WILHELM, K. "They help to weave the veil": Edgar Salin and the Israel economic and sociological research project. In:BEN-RAFAEL, E.;SCHOEPS, J. H; STERNBERG,Y.; GLOECKNER, O. (Org.). Handbook of Israel: major debates. Berlin: Mendelssohn Foundation, p. 1134-1160, 2016.

WYPLOSZ, C.Viewpoint. The Euro's finest hour? Finance \& Development. v. 46, n. 2, p. 22-24, 2009. 